\title{
Hepatitis E Virus Seroprevalence Among Blood Donors in Bushehr, South of Iran
}

\author{
Behrouz Naeimi, ${ }^{1,2}$ Farnaz Mazloom Kalimani, ${ }^{3}$ Ali Akbar Pourfatolah, ${ }^{4}$ Masoud Azimzadeh, ${ }^{3}$ \\ Alireza Mankhian, ${ }^{5}$ Samad Akbarzadeh, ${ }^{6}$ Gholamreza Hajiani, ${ }^{5}$ Faramarz Kooshesh, ${ }^{7}$ and \\ Gholamreza Khamisipour ${ }^{2,8, *}$ \\ ${ }^{1}$ Department of Microbiology and Parasitology, Faculty of Medicine, Bushehr University of Medical Sciences, Bushehr, IR Iran \\ ${ }^{2}$ The Persian Gulf Tropical Medicine Research Center, Bushehr University of Medical Sciences, Bushehr, IR Iran \\ ${ }^{3}$ Student Research Committee, Bushehr University of Medical Sciences, Bushehr, IR Iran \\ ${ }_{5}^{4}$ Department of Immunology, Faculty of Medical Sciences, Tarbiat Modares University, Tehran, IR Iran \\ ${ }_{6}^{5}$ Bushehr Blood Transfusion Organization, Bushehr, IR Iran \\ ${ }^{6}$ Department of Biochemistry, Faculty of Medicine, Bushehr University of Medical Sciences, Bushehr, IR Iran \\ 7 Department of Surgical Technology, Faculty of Allied Medicine, Bushehr University of Medical Sciences, Bushehr, IR Iran \\ ${ }^{8}$ Department of Hematology, Faculty of Allied Medicine, Bushehr University of Medical Sciences, Bushehr, IR Iran \\ *Corresponding Author: Gholamreza Khamisipour, Department of Hematology, Faculty of Allied Medicine, Bushehr University of Medical Sciences, Bushehr, IR Iran. Tel: +98-9123337806, \\ Fax:+98-7733450161, E-mail: r.khamisipour@bpums.ac.ir; ghr.khamisi@gmail.com
}

Received 2015 April 12; Revised 2015 August 19; Accepted 2015 September 26.

\begin{abstract}
Background: Although so far several studies have determined the hepatitis E virus (HEV) prevalence in some parts of Iran, no data exists regarding the HEV seroprevalence in Bushehr province as the southernmost point in Iran yet.

Objectives: The aim of this study was to evaluate the seroprevalence of anti-HEV IgG among the blood donors in Bushehr.

Patients and Methods: A total of 628 blood donor samples were collected from September to October 2013, after obtaining informed written consents, and analyzed for the presence of anti-HEV IgG using commercial HEV enzyme-linked immunosorbent assay (ELISA) kit. All the samples were tested by two ELISA kits and evaluated for liver function test.

Results: Overall, 105 (16.7\%) blood samples were positive for HEV-specific-IgG antibodies, while 523 (83.8\%) were negative. The presence of anti-HEV IgG was not associated with gender; however, it was correlated with age. It was indicated that the anti-HEV prevalence increases by age and there was a significant difference between the age groups regarding HEV seropositivity.

Conclusions: High HEV seroprevalence (16.7\%) was observed among the blood donors in Bushehr province. It appears that exposure to HEV increases with age; although, more people should be examined.
\end{abstract}

Keywords: Hepatitis E Virus, Seroepidemiological Studies, Enzyme-Linked Immunosorbent Assay, Blood Donors, Iran

\section{Background}

Hepatitis E virus (HEV) infection is commonly an acute hepatitis infection caused by a non-enveloped, singlestranded RNA virus belonging to genus Hepevirus, family Hepeviridae (1). This virus remains infectious in sewage; therefore, it can be transmitted by fecal-oral route, especially faeces-contaminated water in developing countries $(1,2)$. Blood transfusion and zoonotic HEV infection have a role in the spread of the virus in developed countries where sporadic cases of HEV infection have been reported (3). There is some evidence suggesting that persons who receive blood from HEV infected blood donors experience acute hepatitis after blood transfusion (4). This virus has infected one-third of the world population (5). The clinical symptoms of HEV infection are acute, self-limited hepatitis in healthy individuals (6). Pregnant women and patients with underlying liver disease are at high risk of fulminant and fatal HEV infection (1, 7-9).

According to what was said, HEV is a considerable public health problem all around the world, especially in developing countries due to poor sanitation and lack of sewage infrastructures (10). Although epidemiological data shows that HEV infection is endemic in developing countries of Asia, Africa, and the Middle East, it has been proved that this infection is also increasing in developed countries (10).

\section{Objectives}

There has been relatively little research on the prevalence of HEV in Iran; therefore, this study was an attempt to address the issue of the high seroprevalence of HEV among voluntary blood donors in Bushehr, Iran.

Copyright (C) 2015, Kowsar Corp. This is an open-access article distributed under the terms of the Creative Commons Attribution-NonCommercial 4.0 International License (http://creativecommons.org/licenses/by-nc/4.0/) which permits copy and redistribute the material just in noncommercial usages, provided the original work is properly cited. 


\section{Patients and Methods}

This study was approved by the Ethics Committee of Bushehr University of Medical Sciences and Bushehr Blood Transfusion Organization to estimate the presence of HEV in voluntary healthy blood donors. Based on previous studies and the reported prevalence (11.5\%) in other areas in southwest of Iran (2) as well as the confidence level of $95 \%$ and an estimated error of $2.5 \%$, the required sample size was 626 . In the present study, 628 anonymized blood samples during a cross-sectional study were collected from Iranian Blood Transfusion Organization from September to October 2013. Blood samples were collected after completing the standard questionnaires (11) and obtaining the formal written consent of Bushehr University of Medical Sciences. All the samples were analyzed for IgG antibody against HEV. The presence of anti-HEV antibody in human sera was tested by a commercial enzyme-linked immunosorbent assay (ELISA) kit (HEV IgG, Pasto, Iran) according to the manufacturer's instructions. All of the reactive samples were analyzed by liver functional tests including albumin, bilirubin, serum glutamic oxaloacetic transaminase (SGOT), and serum glutamic pyruvic transaminase (SGPT) to determine acute HEV infection and were rechecked by Second ELISA kit (HEV IgG/IgM; DIA.PRO Srl, Milan, Italy). All the samples were negative for HIV-antibody (Ab), hepatitis B surface antigen (HBs$\mathrm{Ag}$ ), and hepatitis $\mathrm{C}$ virus antibody (HCV-Ab).

\subsection{Statistical Analysis}

All the statistical analyses were carried out by SPSS 16 program (SPSS Inc., Chicago, IL, USA). Descriptive indices, chi-squared and t-test were also used to analyze the data. $P$ value $<0.05$ was considered as the significance level.

\section{Results}

A total of 628 blood donors participated in this study; 598 (95.2\%) were male and 30 (4.8\%) were female with a mean age of 36.3 years (ranging from 19 to 65 years). Of the 628 blood donors, 76 (12.1\%) were first-time donors, 450 (71.7\%) were regular donors, and others (16.2\%) had a record of donation; 401 (63.9\%) donors were younger than 40 , while 220 (35\%) were between 40 - 60 years old and $7(1.1 \%)$ were older than 60 years. General characteristics of all the donors are summarized in Table 1. All the donors were normal for liver function tests which indicated the absence of acute hepatic infection. With regard to age, anti-HEV IgG antibodies were positive in 14 (3.5\%) in the group younger than 40, $86(39.1 \%)$ in the group 40 - 60 years, and 5 (71.4\%) in the group older than 60 years. Therefore, it indicated that the anti-HEV prevalence increased by increase of age and there was a significant difference between the age groups regarding HEV seropositivity $(\mathrm{P}=0.001)$. Regarding the analysis of the subjects according to gender, 100 (16.7\%) in the male group and 5 (16.7\%) in the female group were positive for anti-HEV IgG antibodies. However, the difference between males and females was not significant $(\mathrm{P}=0.614)$. Overall, 105 blood samples (16.7\%) showed positive HEV-specific-IgG antibodies while 523 (83.8\%) donors were negative (Table 1).

\section{Discussion}

Anti-HEV IgG antibody is a demonstrator of past infection and can be used for studying the HEV epidemiology. HEV prevalence has been determined in different parts of Iran which is considered as an endemic country for HEV infection $(4,6)$. However, there are no documented data regarding the HEV prevalence in Bushehr province. Therefore, we measured the anti-HEV seroprevalence among healthy blood donors in Bushehr and noticed a prevalence of $16.7 \%$, which was higher than what was reported among Iranian blood donors (Table 2).

Table 1. Results of Anti-Hepatitis E Virus Reactivity in Blood Volunteers in South of Iran ${ }^{a, b}$

\begin{tabular}{|c|c|c|c|}
\hline Variables & All Donors & HEV-Negative & HEV-Positive \\
\hline Overall seropositivity & 628 & $523(83.3)$ & $105(16.7)$ \\
\hline \multicolumn{4}{|l|}{ Gender } \\
\hline Male & $598(95.2)$ & $498(83.3)$ & $100(16.7)$ \\
\hline Female & $30(4.8)$ & $25(83.3)$ & $5(16.7)$ \\
\hline \multicolumn{4}{|l|}{ Age, $y$} \\
\hline$<40$ & $401(63.9)$ & $387(95.5)$ & $14(3.5)$ \\
\hline $40-60$ & $220(35)$ & $134(60.9)$ & $86(39.1)$ \\
\hline$>60$ & $7(1.1)$ & $2(28.6)$ & $5(71.4)$ \\
\hline
\end{tabular}

a Abbreviation: HEV, hepatitis E virus

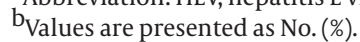


Naeimi B et al.

Table 2. Anti-Hepatitis E Virus Seroprevalence in Iran

\begin{tabular}{lccc}
\hline City & Geographical Position in Iran & Seroprevalence $^{\mathbf{a}}$ & \multicolumn{1}{c}{ References $^{-}$} \\
\hline Arak & Centre & 14.3 & $(4)$ \\
Tehran & North & 7.8 & $(12)$ \\
Tehran & North & 9.3 & $(13)$ \\
Tabriz & Northwest & 7.8 & $(14)$ \\
Hamadan & West & 12.9 & $(13)$ \\
Ahvaz & Southwest & 11.5 & $(2)$ \\
Nahavand & West & 9.3 & $(15)$ \\
\hline
\end{tabular}

$\mathrm{a}_{\text {Values unit is \%. }}$

The HEV seroprevalence among the general population of developed countries is low $(0.4 \%-3.9 \%)(6)$. According to our results, a high HEV seroprevalence rate of $16.7 \%$ was observed among volunteer the blood donors in Bushehr province, which was higher than those obtained among the blood donors in Switzerland (4.9\%) (9), Brazil (2.3\%) (16), and France (3.20\%) (17). However, it was less than the reported values of blood donors in China (27.42\% and 32.60\%) (18, 19), Saudi Arabia (18.7\%) (20), and The Netherlands (27\%) (21).

We noticed that the HEV seroprevalence increased with age and there was a significant association between age and higher HEV prevalence. This finding agrees with a similar study in Isfahan, Iran, which showed that HEV seropositivity increased with age from $0.9 \%$ in children to about $8 \%$ in subjects aged over 50 years (22). Seropositivity was $3.5 \%$ in people aged below 40 years and $71.4 \%$ in people over 60 years old. In the present study, no association between gender and HEV seroprevalence was detected and none of the suited samples were positive for HIV, HBV, and HCV infectious markers. Similar results were reported by most other studies $(4,6,9,21)$.

In conclusion, the high HEV seroprevalence of $16.7 \%$ was observed among the blood donors in Bushehr province, Iran. According to our results, we came to this conclusion that Bushehr province is an endemic area for HEV infection. It appears that exposure to HEV increases with the increase of age; although, more people should be examined. Epidemiological information regarding HEV prevalence is important in evaluating the safety of blood products. However, further studies are needed to assess this matter with studying more populations and considering similarity of numbers of each studied group according to gender and age.

\section{Acknowledgments}

We would like to acknowledge Bushehr University of Medical Sciences and appreciate Bushehr Blood Transfusion Centre for their supports.

\section{Footnotes}

Authors' Contribution:Gholamreza Khamisipour: design and managing the project, editing, and preparing the initial draft; Behrouz Naeimi: implementation of study and editing; Farnaz Mazloom Kalimani and Alireza Mankhian: performing the tests; Faramraz Kooshesh and Masoud Azimzadeh: collecting the samples and preparing the questionnaire; Ali Akbar Pourfatolah and Samad Akbarzadeh: editing the paper; Gholamreza Hajiani: financial and technical support in blood transfusion center.

Funding/Support:This study was funded by Bushehr Blood Transfusion Organization and Bushehr University of Medical Sciences.

\section{References}

1. Taherkhani R, Makvandi M, Farshadpour F. Development of enzymelinked immunosorbent assays using 2 truncated ORF2 proteins for detection of IgG antibodies against hepatitis E virus. Ann Lab Med. 2014;34(2):118-26.doi:10.3343/alm.2014.34.2.118. [PubMed:24624347]

2. Assarehzadegan MA, Shakerinejad G, Amini A, Rezaee SA. Seroprevalence of hepatitis $\mathrm{E}$ virus in blood donors in Khuzestan Province, southwest Iran. Int J Infect Dis. 2008;12(4):387-90. doi: 10.1016/j.ijid.2007.09.015. [PubMed: 18063401]

3. Cheng XF, Wen YF, Zhu M, Zhan SW, Zheng JX, Dong C, et al. Serological and molecular study of hepatitis $\mathrm{E}$ virus among illegal blood donors. World J Gastroenterol. 2012;18(9):986-90. doi: 10.3748/wjg.v18.i9.986. [PubMed: 22408360]

4. Ehteram H, Ramezani A, Eslamifar A, Sofian M, Banifazl M, Ghassemi S, et al. Seroprevalence of Hepatitis E Virus infection among volunteer blood donors in central province of Iran in 2012. Iran J Microbiol. 2013;5(2):172-6. [PubMed: 23825737]

5. Zhu FC, Zhang J, Zhang XF, Zhou C, Wang ZZ, Huang SJ, et al. Efficacy and safety of a recombinant hepatitis $\mathrm{E}$ vaccine in healthy adults: a large-scale, randomised, double-blind placebo-controlled, phase 3 trial. Lancet. 2010;376(9744):895-902. doi:10.1016 S0140-6736(10)61030-6. [PubMed: 20728932]

6. Sepanlou S, Rezvan H, Amini-Kafiabad S, Dayhim M, Merat S. A Population-based Seroepidemiological Study on Hepatitis E Virus in Iran. Middle East J Dig Dis. 2010;2(2):97-103. [PubMed: 25197520]

7. Wang L, Zhuang H. Hepatitis E: an overview and recent advances in vaccine research. World J Gastroenterol. 2004;10(15):2157-62. [PubMed:15259057]

8. Emerson SU, Purcell RH. Running like water--the omnipresence of hepatitis E. N Engl J Med. 2004;351(23):2367-8. doi: 10.1056/ NEJMp048285. [PubMed:15575050]

9. Kaufmann A, Kenfak-Foguena A, Andre C, Canellini G, Burgisser P, Moradpour D, et al. Hepatitis E virus seroprevalenceamong blood donors in southwest Switzerland. PLoS One. 2011;6(6):e21150. doi: 10.1371/journal.pone.0021150. [PubMed: 21701586]

10. Hoofnagle JH, Nelson KE, Purcell RH. Hepatitis E. N Engl J Med 2012;367(13):1237-44. doi: 10.1056/NEJMra1204512. [PubMed: 23013075]

11. Hadi N, Khademalhosseini M. Comparison of Prevalence of Fatigue in Adult Diabetic Mellitus Patients with Healthy Population in Shiraz 2010. Shiraz E-Med J. 2012;13(3):1-8. 
12. Mohebbi SR, Rostami Nejad M, Tahaei SM, Pourhoseingholi MA, Habibi M, Azimzadeh P, et al. Seroepidemiology of hepatitis $A$ and $E$ virus infections in Tehran, Iran: a population based study. Trans R Soc Trop Med Hyg. 2012;106(9):528-31. doi: 10.1016/j. trstmh.2012.05.013. [PubMed:22835757]

13. Alavian SMF, Bagheri Lankarani K. Epidemiology of Hepatitis E in Iran and Pakistan. Hepat Mon. 2009;9(1):60-5.

14. Taremi M, Gachkar L, MahmoudArabi S, Kheradpezhouh M Khoshbaten M. Prevalence of antibodies to hepatitis E virus among male blood donors in Tabriz, Islamic Republic of Iran. East Mediterr Health J. 2007;13(1):98-102. [PubMed: 17546911]

15. Taremi M, Alizadeh AH, Ardalan A, Ansari S, Zali MR. Seroprevalence of hepatitis E in Nahavand, Islamic Republic of Iran: a population-based study. East Mediterr Health J. 2008;14(1):157-62. [PubMed: 18557463]

16. Bortoliero AL, Bonametti AM, Morimoto HK, Matsuo T, Reiche EM. Seroprevalence for hepatitis E virus (HEV) infection among volunteer blood donors of the Regional Blood Bank of Londrina, State of Parana , Brazil. Rev Inst Med Trop Sao Paulo. 2006;48(2):87-92. doi: 10.1590/s0036-46652006000200006. [PubMed:16699630]

17. Boutrouille A, Bakkali-Kassimi L, Cruciere C, Pavio N. Prevalence of anti-hepatitis E virus antibodies in French blood donors. Clin Microbiol. 2007;45(6):2009-10. doi: 10.1128/JCM.00235-07. [PubMed: 17460057]

18. Ren F, Zhao C, Wang L, Wang Z, Gong X, Song M, et al. Hepatitis E virus seroprevalence and molecular study among blood donors in China. Transfusion. 2014;54(3 Pt 2):910-7. doi: 10.1111/trf.12530. [PubMed: 24372259]

19. Guo QS, Yan Q, Xiong JH, Ge SX, Shih JW, Ng MH, et al. Prevalence of hepatitis E virus in Chinese blood donors. J Clin Microbiol. 2010;48(1):317-8. doi: 10.1128/JCM.01466-09. [PubMed:19940058]

20. Johargy AK, Mahomed MF, Khan MM, Kabrah S. Anti hepatitis E virus seropositivity in a group of male blood donors in Makkah, Saudi Arabia. J Pak Med Assoc. 2013;63(2):185-9. [PubMed: 23894892]

21. Slot E, Hogema BM, Riezebos-Brilman A, Kok TM, Molier M, Zaaijer HL. Silent hepatitis E virus infection in Dutch blood donors, 2011 to 2012. Euro Surveill. 2013;18(31):20550. [PubMed: 23929229]

22. Ataei B, Nokhodian Z, Javadi AA, Kassaian N, Shoaei P, Farajzadegan Z, et al. Hepatitis $E$ virus in Isfahan Province: a population-based study. Int J Infect Dis. 2009;13(1):67-71. doi: 10.1016/j. ijid.2008.03.030. [PubMed:18599335] 